\title{
The Research on the Agglomeration of Beijing-Tianjin-Hebei Industry
}

\author{
Bu Hongyun ${ }^{1, a}$, Li Hongshan ${ }^{2, b}$ \\ ${ }^{1}$ School of Economics and Management, Yanshan University, Qinhuangdao,Hebei,China \\ ${ }^{2}$ School of Economics and Management, Yanshan University, Qinhuangdao,Hebei,China \\ abhyun@ysu.edu.cn, ${ }^{b}$ lihongshan1987@sina.com
}

Keywords: Beijing-Tianjin-Hebei industry; agglomeration degree; combined effect; location entropy; CES production function

\begin{abstract}
Based on location entropy model, this paper adopts the 10-year moving average method calculating the agglomeration of Beijing-Tianjin-Hebei industry .Then, the industrial data of Beijing-Tianjin-Hebei were calculated and made regression using the CES production function to analyze the combined effect of Beijing-Tianjin-Hebei. Finally, the regression results in all regions of Beijing, Tianjin and Hebei were horizontally contrasted to determine the industrial agglomeration characteristics of the areas and put forward relevant recommendations.
\end{abstract}

\section{Introduction}

Generally, industrial cluster refers to a particular industry and its related supporting industries, or different type of industries concentrating within a certain geographical range. [1] In order to achieve industrial concentration, many regions have also been planned. And in all of the major plans of the State on the city circle, the most rapid development region was Beijing-Tianjin-Hebei, which is likely to be the third pole of economic growth in China. Industry, recently developing unique, is the main industry in this region. Such as Beijing's industry that is mainly industry transferring, therefore, to study the industrial development of this region is Significant. Based on the view of industrial clusters, this article calculates quantitatively the industrial agglomerations and agglomeration effects of Beijing, Tianjin and Hebei, and attempts to explore the landscape relationships of its internal.

\section{Industrial agglomeration and agglomeration effect}

Based on the differences in the size of regions, the regional differences in terms of economy, population will be significant, to compare the market share directly is not clearly display the superior industry of an area and therefore requiring appropriate indicators to rule out regional differences in the size. The advantage of Entropy index is simple and convenient, which can more vividly reflect the level of industrial concentration.

CES (Constant Elasticity of Substitution) production function, that is constant elasticity of substitution production function, is the logarithmic model; which can effectively reduce the impact of heteroskedasticity in regression procedure, and its performance is superior to a simple linear model. P.J.Dhrymes (1965) creative made a scale coefficient h:

$$
h=\frac{1+\beta}{1-\gamma}
$$

In the equation, $h$ represents a return to scale parameter in order to measure effects of the agglomeration. Because the economy of scale is assumed by P.J.Dhrymes that the market is imperfect competition, this function is used more common. At the time of application, Jie Tang improved the CES production function like this:

$$
P=A Q^{\beta} K^{\gamma}
$$

This formula measured industrial agglomeration economies at the level of city. $\gamma$ is the profit elasticity occupied by fixed assets; $\beta$ represents the profit elasticity of output; $K$ represents the 
net value of fixed assets of some year; $P$ is profit of industrial sector.

Improved function uses the net fixed asset value, total profit and total industrial output value and other factors of regression analysis to measure the regional agglomeration economy effect, and to describe the internal mechanism that makes profits and the use of fixed asset efficiency reality. If the values of other elements do not change, and total fixed asset investment increases, per unit fixed assets value will increase, which will result in increased costs, further the agglomeration economy effect (h) will reduce [3].

By formula (2), we get the improved on both sides of the equation: $\ln P=\ln A+\beta \ln Q+\gamma \ln K$, then taking samples value of $K, P$ and $Q$ into equation to return analysis, so as to work out the value of $\beta 、 \gamma$, and finally using formula (5)to work out the value of industry agglomeration effect $h$. Evaluating the regional industrial agglomeration economy effect objectively based on the value of $H$. If $H<1$, industry did not produce effects in the region; $H>1$, regional industry increasing return to scale, which means agglomeration effects existing.

\section{Beijing-Tianjin-Hebei regional empirical analysis of industrial agglomeration}

\subsection{Calculation of industrial agglomeration}

This article selects the data of Jing-Jin-JI region as well as the country's added value of GDP and industrial during 1990--2010, computing the entropy values of industrial agglomeration of Beijing, Tianjin and Hebei region. In order to contrast to the behind of the agglomeration effect, This document describes the location entropy values during each ten-year period for the moving average, so you can remove the fluctuations of random interference, which better reflect the location entropy values of long-term trends. Concrete results are shown in table 1:

Table1 Entropy index of industrial agglomeration of Beijing-Tianjin-Hebei (s)

\begin{tabular}{ccccc}
\hline year & Beijing-Tianjin-Hebei s1 & Tianjin s2 & Hebei s3 & Beijing s4 \\
\hline Table1990-1999 & 1.0438 & 1.2595 & 1.0502 & 0.9022 \\
$1991-2000$ & 1.0216 & 1.2287 & 1.0505 & 0.8489 \\
$1992-2001$ & 1.0021 & 1.2014 & 1.0542 & 0.7977 \\
$1993-2002$ & 0.9833 & 1.1801 & 1.0570 & 0.7496 \\
$1994-2003$ & 0.9661 & 1.1672 & 1.0529 & 0.7147 \\
$1995-2004$ & 0.9578 & 1.1638 & 1.0583 & 0.6876 \\
$1996-2005$ & 0.9547 & 1.1613 & 1.0722 & 0.6608 \\
$1997-2006$ & 0.9508 & 1.1630 & 1.0832 & 0.6362 \\
$1998-2007$ & 0.9482 & 1.1692 & 1.0951 & 0.6136 \\
$1999-2008$ & 0.9474 & 1.1795 & 1.1076 & 0.5899 \\
$2000-2009$ & 0.9473 & 1.1872 & 1.1194 & 0.5700 \\
$2001-2010$ & 0.9474 & 1.1921 & 1.1293 & 0.5528 \\
\hline
\end{tabular}

\subsection{Calculation of the agglomeration effect}

We choose the data of owned industrial enterprises in Beijing, Tianjin and Hebei region during 1990-1997, all State-owned and non-State-owned above designated size industrial enterprises in Beijing, Tianjin and Hebei area between 1998-2006, and the industrial output value of industrial enterprises above the designated size $\mathrm{Q}$, $\mathrm{k}$ and annual average balance of net value of fixed assets total profits p of Beijing, Tianjin and Hebei area between 2007-2010, implicating of SPSS17.0 into log-transformed CES production function to make regression analysis. The equation regression is successful on the whole.

Further, selecting the return parameter $\beta$ and $\gamma$ of various parts, and substitute them into formula (1) to get agglomeration effect indices shown in table 2: 
Table2 Beijing-Tianjin-Hebei regional agglomeration effect indices (h)

\begin{tabular}{ccccc}
\hline year & Jing-Jin-JI h1 & Tianjin h2 & Hebei h3 & Beijing h4 \\
\hline $1990-1999$ & 1.5083 & 1.9695 & 1.7229 & 1.1500 \\
$1991-2000$ & 1.5574 & 2.1047 & 1.7656 & 1.2507 \\
$1992-2001$ & 1.5786 & 2.1255 & 1.8680 & 1.2695 \\
$1993-2002$ & 1.6412 & 2.1653 & 1.8308 & 1.2431 \\
$1994-2003$ & 1.7950 & 2.0865 & 2.1918 & 1.5004 \\
$1995-2004$ & 1.8731 & 1.9386 & 3.2853 & 1.1399 \\
$1996-2007$ & 1.7804 & 1.9727 & 4.2566 & 1.1474 \\
$1999-2008$ & 1.1937 & 1.1034 & 1.6070 & 1.4450 \\
$2000-2009$ & 1.4851 & 1.4071 & 1.5373 & 1.6393 \\
$2001-2010$ & 1.7039 & 1.8241 & 1.6909 & 1.6333 \\
\hline
\end{tabular}

\subsection{Decomposition of the agglomeration effect}

In order to study on the effect more in-depth, based on the foregoing analysis of agglomeration economies, the overall agglomeration economy effect can be broken down into:

1. ISE: internal agglomeration economies. ISE= an industry in a particular sector in the period of fixed assets / number of companies in the sector

2. LOC: layout of agglomeration economies. Economic location or the location or layout of the economy was affected by natural factors, economic factors and social factors arising from the combined effect of agglomeration effects.

3. URB: urban agglomeration economies. Refer to the industry as companies take advantage of specialized division of labor among them to form agglomeration effects. This article assume linear model to break down aggregation effect h: $h=a+b I S E+c L O C+d U R B$

The results of industry aggregation effect h decomposition are shown in table 3 :

Table 3 Decomposition variables regression coefficients

\begin{tabular}{ccccc}
\hline Decomposition variable & Beijing & Tianjin & Hebei & Beijing-Tianjin-Hebei \\
\hline ISE & $5.255 \mathrm{E}-5$ & $7.147 \mathrm{E}-5$ & $2.100 \mathrm{E}-6$ & $7.113 \mathrm{E}-5$ \\
LOC & -0.248 & -4.729 & 2.068 & 1.092 \\
UBE & 0 & 0 & 0 & 0 \\
\hline
\end{tabular}

As shown in table 3: (1) at the aspects of internal gather; Three regions show the positive aggregation effect, as to the magnitude of the regression parameters $(\mathrm{E}-*)$, it is determined by the magnitude of the ISE (USD/business). If changes in fixed assets by 100 million, the parameter for the 1E-1of ISE caused aggregation effect changes of 0.1 . Due to the internal gathering arising from agglomeration economies: Tianjin> Beijing>Beijing-Tianjin-Hebei>Hebei. (2) In terms of layout of agglomeration economies. The Layout agglomeration economies of Beijing and Tianjin are negative. By described previously, Beijing's failure to obtain the long run average costs caused by the layout gathered economy; however, the gathering brought larger layout agglomeration diseconomies of Tianjin. Beijing, Tianjin and Hebei had small layout aggregation effect as a whole. (3) From the perspective of urban agglomeration economies, three areas, as well as Beijing, Tianjin and Hebei overall regression parameter is 0 , indicating that none of the three industrial had urban agglomeration economies. [4] [5]

\section{Recommendations}

On the base of analyzing Beijing-Tianjin-Hebei industrial agglomeration and clustering effect, we believe that the development of Beijing-Tianjin-Hebei industries should be as follows: 1 . Hebei and Tianjin should continue to strengthen input into the high-tech industry, through the construction of the high-tech Park, increasing dependence on industrial development of science and technology.2. Hebei and Tianjin should further optimize the industrial structure, increasing the proportion of the 
tertiary industry in the economy.3. In the Beijing-Tianjin-Hebei region, Beijing should give full play to their proliferation and the leading role of science and technology, improving the service level of regional tertiary industry. And the industry complementary of Beijing, Tianjin and Hebei is larger than competitive, industry of Hebei and Tianjin would focus on cooperation between enterprises, further strengthen cooperation to make coordinated and stable development of Beijing-Tianjin-Hebei industry as a whole.

\section{References}

[1] Li Xiaojian, Li Erling, in: Comparative Study on Industry Agglomeration Mechanism, edited by Academic Journal of Zhongzhou, Zhengzhou, No. 4 (2002) , p. 5-8.

[2] Zhang Jianhua, Zhang Shujing, in: Research on the Criterion of Identifying Industrial Cluster, edited by China soft science, Beijing, No. 3 (2006) , p. 83-90.

[3] Wang Shulin, Dai Bing, in: Analysis of Heilongjiang Industrial Agglomeration Effect Based on CES Model, edited by Market Modermization, No. 8 (2007) , p. 339-340.

[4] Zhang Lei: Research on Urban System and Evolution Mechanism of Three Metropolis Circle in Eastern China, Ph.D. Thesis, Fu Dan University, Shanghai (2008).

[5] Yu Ming: A Study on Chinese Industrial Agglomeration And the Regional Economic Growth, Ph.D. Thesis, Liaoning University, liaoning (2007). 